Portland State University

PDXScholar

9-10-1993

\title{
Mapping the Distribution of Vesicular Textures on Silicic Lavas Using the Thermal Infrared Multispectral Scanner
}

Jaime Ondrusek

Arizona State University

Philip R. Christensen

Arizona State University

Jonathan Fink

Portland State University, jon.fink@pdx.edu

Follow this and additional works at: https://pdxscholar.library.pdx.edu/geology_fac

Part of the Geology Commons, and the Volcanology Commons Let us know how access to this document benefits you.

\section{Citation Details}

Ondrusek, J., Christensen, P. R., \& Fink, J. H. (1993). Mapping the distribution of vesicular textures on silicic lavas using the Thermal Infrared Multispectral Scanner. Journal of Geophysical Research: Solid Earth (1978-2012), 98(B9), 15903-15908.

This Article is brought to you for free and open access. It has been accepted for inclusion in Geology Faculty Publications and Presentations by an authorized administrator of PDXScholar. Please contact us if we can make this document more accessible: pdxscholar@pdx.edu. 


\title{
Mapping the Distribution of Vesicular Textures on Silicic Lavas Using the Thermal Infrared Multispectral Scanner
}

\author{
Jaime Ondrusek, Philip R. Christensen, and Jonathan H. Fink \\ Department of Geology, Arizona State University, Tempe
}

\begin{abstract}
The Thermal Infrared Multispectral Scanner (TIMS) is a potentially powerful tool for mapping detailed chemical variations in silicic lava flows which in turn could expand knowledge of pre-eruption compositional gradients and mixing processes in silicic magma bodies. However, thermal infrared image data may be greatly influenced by the range of vesicular textures which occur on silicic flows. To investigate the effect of vesicularity on TIMS imagery independent of chemical variations, we studied Little Glass Mountain at the Medicine Lake Volcano of northern California, a large rhyolitic flow of uniform composition but textural heterogeneity. The imagery was recalibrated so that the digital number values for a lake in the scene matched a calculated ideal spectrum for water. TIMS spectra for the lava show useful differences in coarsely and finely vesicular pumice data, particularly in TIMS bands 3 and 4. Images generated by ratioing these bands accurately map out those areas known from field studies to be coarsely vesicular pumice. These texture-related emissivity variations are probably due to the larger vesicles being relatively deeper and separated by smaller septa leaving less smooth glass available to give the characteristic emission of the lava. In studies of inaccessible lava flows (as on Mars) areas of coarsely vesicular pumice must be identified and avoided before chemical variations can be interpreted. Remotely determined distributions of vesicular and glassy textures can also be related to the volatile contents and potential hazards associated with the emplacement of silicic lava flows on Earth.
\end{abstract}

INTRODUCTION

Thermal Infrared Multispectral Scanner (TIMS) images are potentially powerful tools for mapping compositional differences in lava flows. Recent geochemical studies of drill cores from silicic flows previously thought to be homogeneous have shown them to be mixtures of several differentend-members varying in both crystallinity and chemistry [Vogel et al., 1989]. This result and the debate surrounding its interpretation [e.g., Blake and Fink, 1987; Carrigan and Eichelberger, 1990; Vogel et al., 1989] highlight the need for more effective ways to map the detailed chemical make-up of silicic lava flows. Lavas preserve a continuous spatial record of part of the eruptive history of a magma. Such information complements evidence found in more widely dispersed explosive products whose emplacement they commonly follow. Taken together, variations in the chemistry and texture of effusive and explosive rocks can be used to reconstruct preeruption compositional gradients and to unravel mixing processes within silicic magma bodies.

Traditional field methods can be inefficient for mapping compositional differences because of the large sizes of some flows, inaccessibility, the intimate scale of mixing, and the difficulty of quickly identifying gradations between the chemical end-members in hand samples. For these reasons, we have sought to develop TIMS as a tool for mapping such geochemical differences. However, in addition to chemical variations, silicic lavas also contain a range of vesicular and glassy textures that may potentially have a large influence on thermal infrared image data. This complication also applies to the ThermalEmission Spectrometer(TES) imaging system currently en route to Mars as part of the Mars Observer mission. One purpose of this paper is to investigate the effects of vesicular lava textures on infrared imagery so that the TIMS and TES instruments may be used subsequently for geochemical mapping of lava flows on Earth and Mars, respectively. In addition, mapping vesicular textures may assist in hazards assessments because these textures have been shown to be strongly influenced by the distribution of volatiles in the lavas [Fink and Manley, 1989; Fink et al., 1992].

Copyright 1993 by the American Geophysical Union.

Paper number 93JB01559.

0148-0227/93/93JB-01559 $\$ 05.00$
Textures in Silicic Lavas

Rhyolitic extrusions commonly exhibit a range of textures from coarsely vesicular to bubble-free. Although there may be a nearcontinuum of rock types from frothy to glassy, previous studies [Fink, 1983; Manley and Fink, 1987; Fink and Manley, 1987] have identified three principal textures on both the upper surfaces and in the fronts of these flows (Figure 1). The upper, 3-5 m thick carapace is composed of light-colored, finely vesicular pumice (FVP) with unconnected vesicles generally less than $1 \mathrm{~mm}$ in diameter. FVP grades downward to a nonvesicular obsidian (OBS) layer which makes up the next $5-15 \%$ of the flow thickness. Beneath or within the OBS in many flows is a low-density coarsely vesicular pumice (CVP) zone in which bubbles range up to $1 \mathrm{~cm}$ in diameter and are commonly interconnected. Buoyancy causes diapirs of CVP to rise to the surfaces of some flows, lifting a selvage of obsidian as well. Thus most flow surfaces are covered by light-colored FVP punctured by subcircular darker outcrops of CVP, with relatively narrow border zones of shiny OBS separating them. The same textural types are also found on some rhyodacite and dacite flows, but are more difficult to distinguish with the unaided eye in these more mafic extrusions [Fink and Manley, 1987; Anderson and Fink, 1992].

The distribution of vesicular textures on active silicic flows has been related to their likelihood to experience explosive behavior during advance [Fink and Manley, 1989]. Certain variations in vesicularity are associated with the volatile content of the lava [Westrich et al., 1988; Anderson and Fink, 1989]. Volatiles are concentrated in the coarse pumice (up to 0.5 weight percent water), whereas the glassy obsidian is relatively dry $(<0.2 \%)$. There is some debate as to how this variation arises, but it is clear that volatile concentration in silicic lavas can result in dangerous explosive activity if flow fronts collapse [Rose et al., 1977; Fink and Manley, 1989; Fink et al., 1992; Fink and Kieffer, 1993].

\section{Field Site: Medicine Lake Volcano}

The Medicine Lake Volcano of northern California (Figure 2) has several large, young silicic lava flows which represent ideal sites to test the efficacy of TIMS in mapping mixed lavas. The flows are late Holocene (ca. 1100 years [Anderson, 1941; Heiken, 1978]) and have virtually no vegetative cover. Of greatest interest from the standpoint 


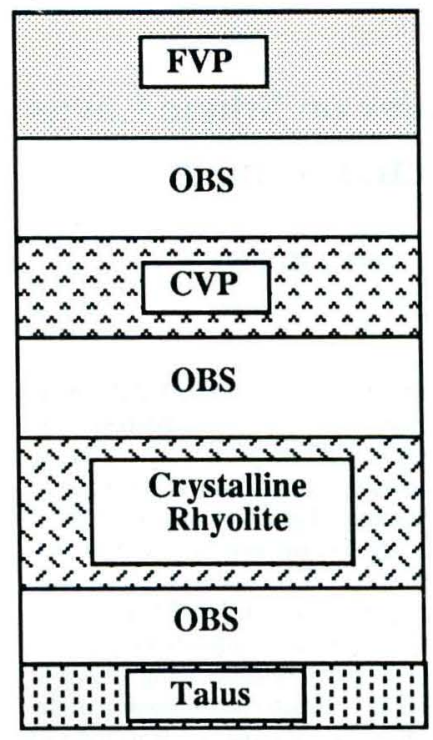

Fig. 1. Schematic cross-section of rhyolitic lava flow (derived from Inyo drill core data). $\mathrm{FVP}=$ finely vesicular pumice forming carapace over flow surface; OBS=obsidian comprising bulk of flow; CVP=internal layer of coarsely vesicular pumice (CVP may also occur at the flow surface as diapirs); crystalline rhyolite forms in the hot core of the flow. of magmatic processes is Glass Mountain, a large flow $\left(1.0 \mathrm{~km}^{3}\right)$ which is compositionally zoned [Eichelberger, 1980; DonnellyNolan et al., 1990] and which preserves abundant evidence of the mixing of different magma types ranging from 64 to $74 \% \mathrm{SiO}_{2}$. However, Glass Mountain also displays a spectrum of vesicular textures whose influence on TIMS images can obscure the chemical variations. Fortunately, nearby Little Glass Mountain (Figure 3) provides an opportunity for separating these effects, because it is essentially the same age as Glass Mountain [Donnelly-Nolan et al., 1990] and exhibits the same range of pumiceous textures, but consists of only the rhyolitic end-member [Donnelly-Nolan, 1988]. In this paper we compare TIMS spectra of CVP, OBS and FVP from Little Glass Moutain in order to identify those effects due entirely to texture. These results will then allow us to map and interpret infrared images of flows of mixed chemistry like Glass Mountain in a followup study.

\section{Methods And Observations}

Although the TIMS instrument operated by NASA has been used successfully to map chemical variations in a variety of crystalline and volcanic rocks [Gillespie et al., 1984; Lahren et al., 1988], and textural differences in basalt (e.g., aa versus pahoehoe [Kahle et al., 1988]), to our knowledge no previous studies have focused exclusively on silicic lavas. TIMS is an aircraft-mounted spectrometer which

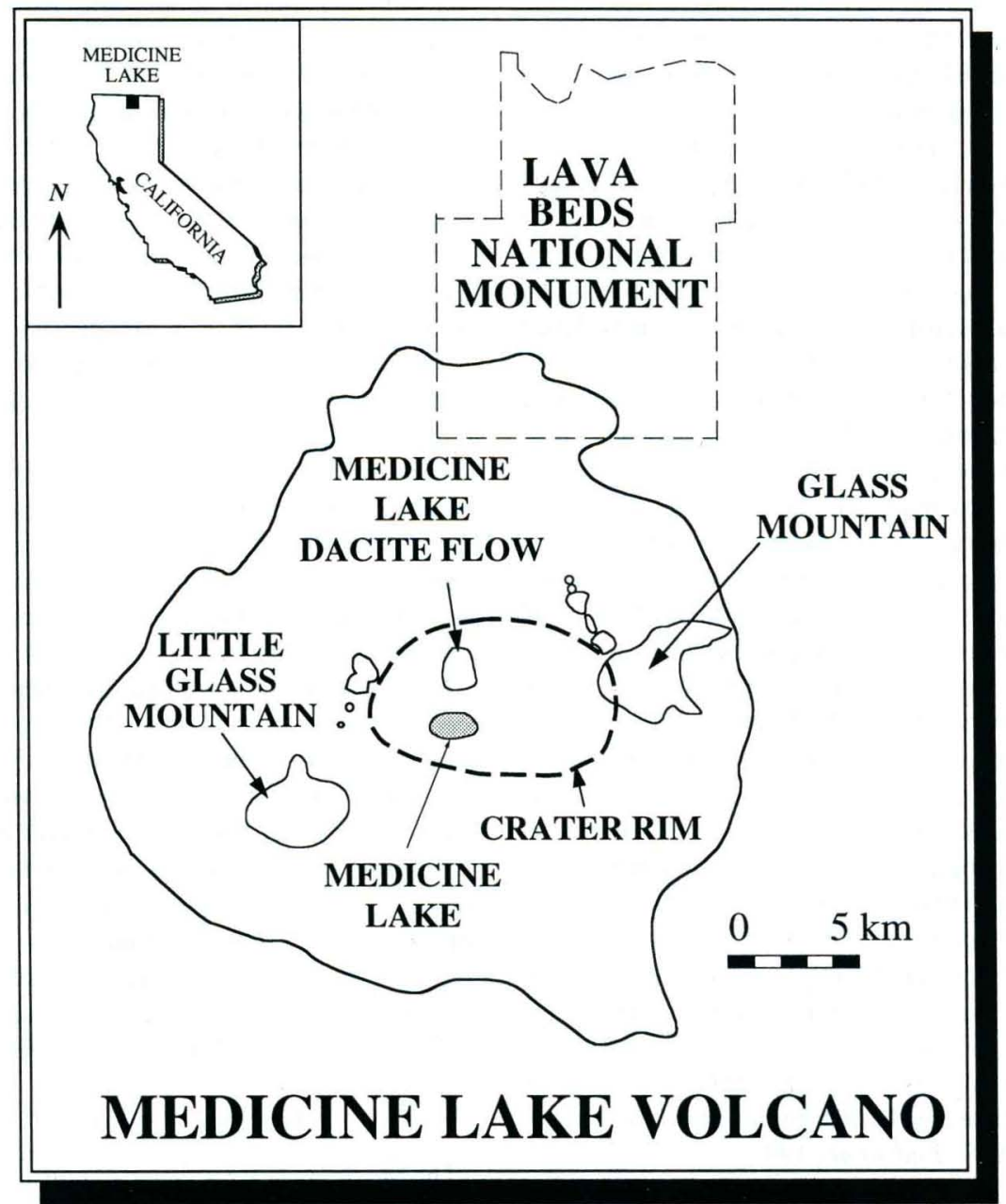

Fig. 2. Location of Medicine Lake Volcano in northern California. North is to the top. Small domes NNE of Little Glass Mountain are Crater Glass flows. Boundary shown for volcano is 5000 foot $(1524 \mathrm{~m})$ contour; volcano actually is more areally extensive. 


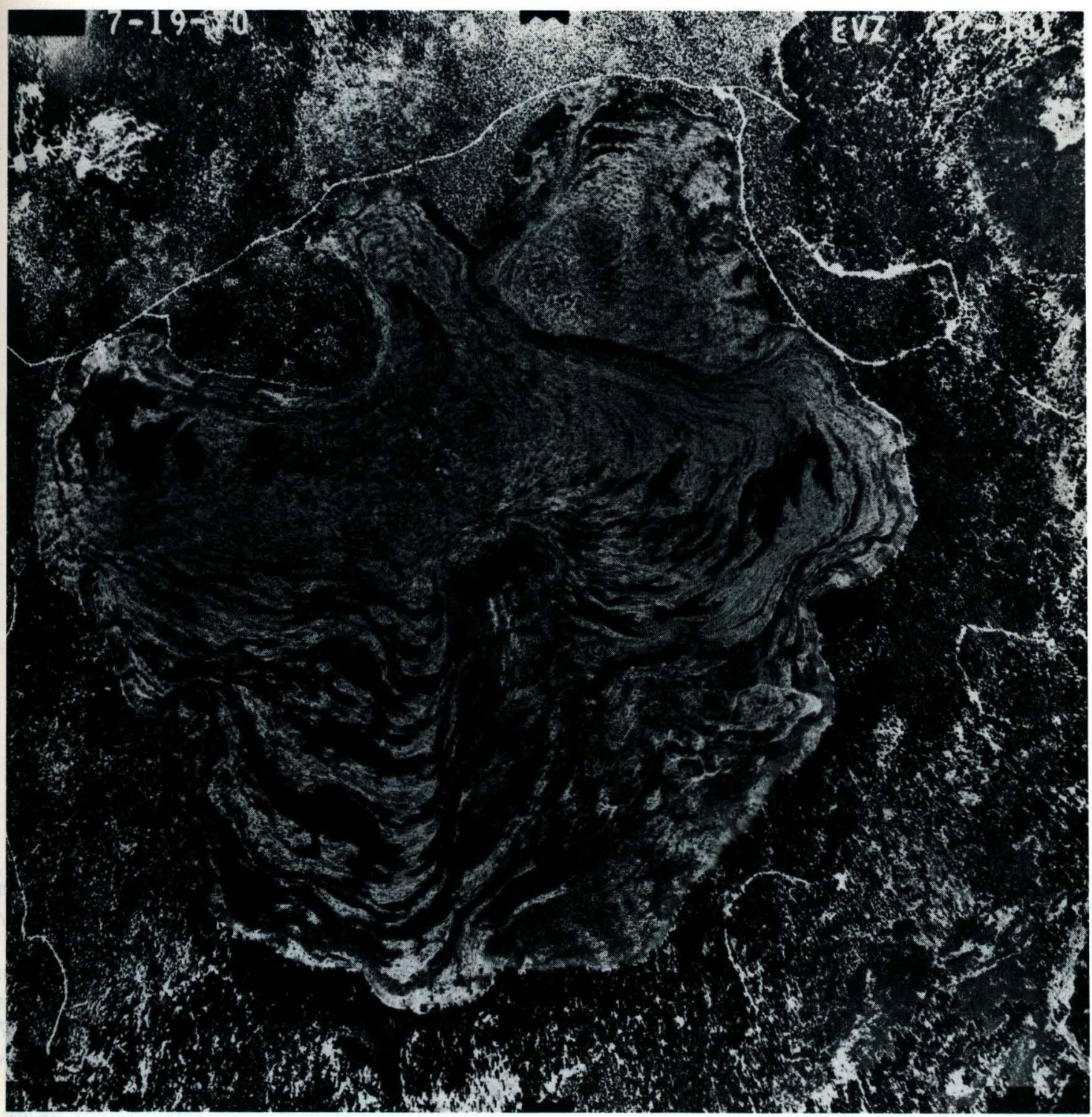

Fig. 3. Aerial photograph of Little Glass Mountain. Flow is approximately $1.6 \mathrm{~km}$ across. Light gray areas are FVP; diapirs of CVP appear dark gray. OBS areas are too small to distinguish.

collects data on the radiance emitted from the ground in six channels spread through the infrared region from 8 to $12 \mu \mathrm{m}$ [Palluconi and Meeks, 1985]. The data are provided in the form of six digital images (one for each band); the value of the digital number in each picture element (pixel) of the image is proportional to the infrared radiance, which in turn depends on the temperature and emissivity of the ground. The emissivity is affected by both the composition and textural properties such as surface roughness and, in the case of disaggregated material, grain size [e.g., Salisbury and Eastes, 1985]. The ability of TIMS to differentiate chemical differences in rocks depends on variations in infrared absorption bands of constituent minerals, which are in turn due to differences in the crystalline lattices of the various minerals. Although infrared signals from glassy rocks are weaker than from crystalline rocks of the same chemistry, compositional variations may still be detected from the former. The digital numbers that make up a TIMS image represent the voltages in solid-state detectors caused by infrared energy emitted from the ground. However, the intervening atmosphere attenuates some of this energy, while adding its own radiance.

Although the TIMS instrument scans internal temperature references for a line-by-line calibration, this calibration may still be in error with respect to actual temperatures and emissivities on the ground. The presence of patches of snow and a lake in the Medicine Lake Volcano scene (acquired in July, 1989) provides a convenient means to independently calibrate the digital numbers (DN) of the image to physical radiance units $\left(\mathrm{mW} / \mathrm{cm}^{2}\right)$. The Planck equation, the infrared emissivity of water [Centeno, 1941]; and data provided by NASA on the spectral response of the TIMS channels were used to calculate an ideal TIMS spectrum for water at various temperatures. This was then compared with actual TIMS spectra for Medicine Lake. The best fit was obtained for a temperature of about $280 \mathrm{~K}$, reasonable for a mountain lake in summer. The calibration was checked by comparing TIMS spectra from snow patches in the scene with an ideal $\mathrm{H}_{2} \mathrm{O}$ spectrum at $0^{\circ} \mathrm{C}$. Radiance values matched to within about $5 \%$.

Six-point TIMS spectra were collected from areas known from field reconnaissance at Little Glass Mountain to be CVP or FVP (Figure 4). Each spectrum is an average of spectra at about 50 individual pixels in various portions of the image known to correspond to CVP or FVP areas on the flow. Error bars represent the standard deviation of the digital numbers (about 4.12 for CVP and 5.32 for FVP). Inspection of Figure 4 reveals some useful thermal absorption 


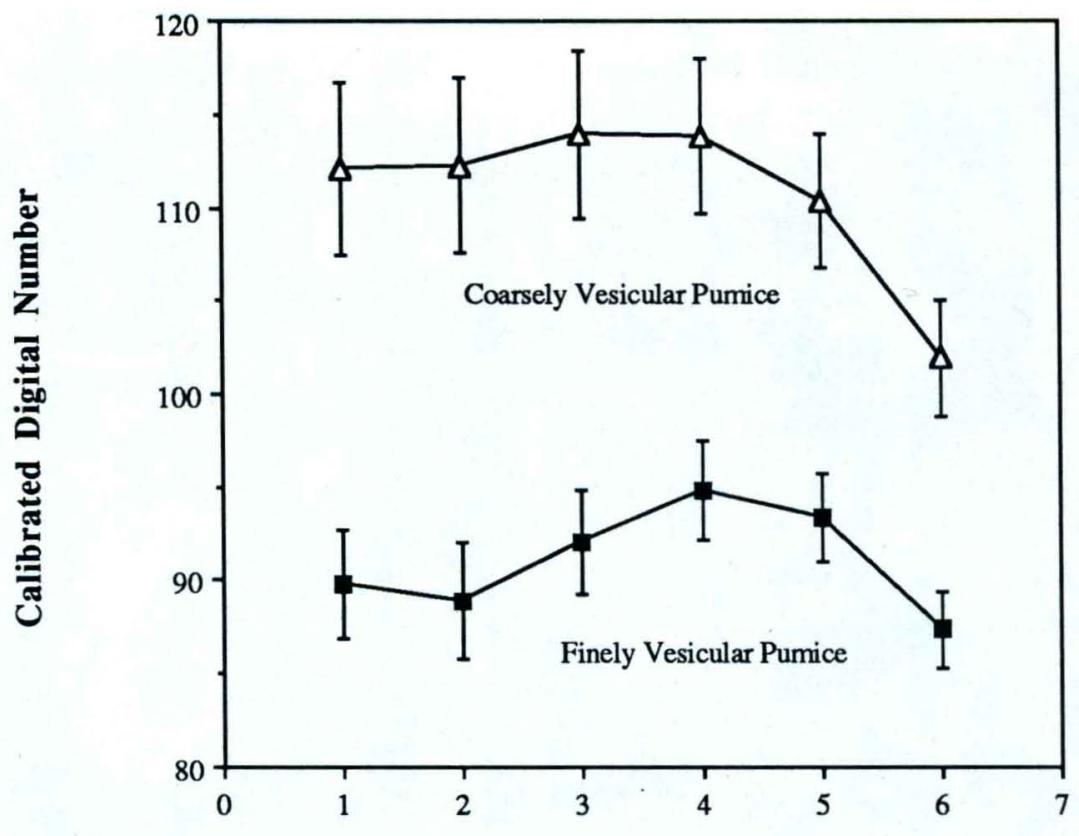

TIMS Band

Fig. 4. Six-point spectra of Little Glass Mountain created from digital numbers of calibrated TIMS image. Open triangles=coarsely vesicular pumice; black squares=finely vesicular pumice. Each spectrum represents an average of about 50 individual pixels. Error bars represent standard deviation of digital numbers for each band. Absorption feature characteristic of isolated silica tetrahedra in glass appears at TIMS Band 2. Comparable data for obsidian could not be obtained because areas of OBS on TIMS image are too small.

and emission features in the TIMS spectra of Little Glass Mountain. Near TIMS Band 2, the FVP spectrum apparently shows the effect of the strong absorption due to the silica tetrahedra in the rhyolitic lava [Lyon, 1965; Salisbury et al., 1988]. The effect seems to be muted in the CVP spectrum. We were concerned with whether this effect was real or some artifact of the system. If real, it could be due to a true emissivity difference between CVP and FVP or a result of the two textures being at different temperatures. To settle this issue, we used a Mattson Cygnus Infrared Spectrometer in the laboratory to collect high-resolution IR spectra of samples of CVP and FVP from Little Glass Mountain. Two spectra of each sample were made, one at $80^{\circ} \mathrm{C}$ and one at $-196^{\circ} \mathrm{C}$; these were combined to create a true emissivity spectrum for each, shown in Figure 5. Clearly, the absorption effect at around 1100 wavenumbers is real and must be due to a true emissivity difference, since the samples were analyzed at controlled temperatures. The absorption effect is visibly weaker in the CVP sample. Referring to the boundaries of the TIMS bands, the absorption feature should be evident in TIMS Band 2, just where it is observed in the Little Glass Mountain data. Also, the CVP spectrum exhibits higher overall emissivity (and therefore higher DN) than the FVP.

In order to distinguish between CVP and FVP in TIMS images, we capitalize on certain differences in slope within the spectra of DN values for the two textures (Figure 4). The slopes of the lines connecting Bands 1 and 2, 5 and 6 , and particularly 3 and 4 vary the most between the CVP and FVP spectra. These slope differences can easily be exploited for imaging purposes by generating a digital image consisting of the ratio of two adjacent TIMS Bands. Figure 6 contains such an image created from a ratio of TIMS Bands 4 and 3 . The spatial resolution is about $4.5 \mathrm{~m}$ per pixel. There is an excellent correspondence between the dark areas on this image (caused by relatively low slopes in the spectra) and the CVPdiapirs coincidentally visible as dark gray on the air photo (Figure 3 ). The majority of the surface of the flow is FVP, which appears light gray on the TIMS image. Most outcrops of OBS are sandwiched between CVP and FVP and are too small to show up on the TIMS images.

\section{Discussion}

Observations at Little Glass Mountain confirm that emissivity variations in thermal data from lava flows can be caused by textural as well as chemical differences. We propose that the contrast between CVP and FVP emissivities is caused by variations in the shapes and abundances of vesicles. FVP bubbles tend to be roughly hemispherical with relatively shallow depth to diameter ratios (Figure $7 b$ ). As a result, they act less like blackbody cavities so their emissivities are more comparable to those from a flat-lying surface (Figure 7a)[Bedford, 1988, Figure 12.3]. Conversely, CVP has deeper, narrower cavities that appear cylindrical, conical, or as parallel plates (Figure $7 c$ ), shapes which all result in significantly higher effective emissivities regardless of the intrinsic properties of the nonvesicular glass. The exact boost depends on the detailed geometry of the cavities, but increases from 0.8 (intrinsic) to 0.95 or greater (cavity) are typical [Bedford, 1988]. This effect can account for the higher overall emissivity of the CVP spectra (Figures 4,5), since a blackbody has an emissivity approaching 1 , while that of a selective radiator is less than 1. Since blackbody emission is independent of the composition of the radiator, CVP from lava flows of different compositions should appear nearly identical in TIMS data. Furthermore, because CVP tends to have a higher abundance of bubbles and thus fewer flat-lying surfaces than FVP, the ability of those bubbles to reduce the spectral contrast relative to either FVPor bubble-free glass is enhanced.

\section{Conclusions}

We have shown that pumiceous textural variations on silicic lava flows can be mapped using TIMS data because vesicularity results in real differences in the IR emissivity of glassy lava. Coarsely vesicular pumice behaves spectrally like a blackbody, and consequently does not provide useful information about composition in IR data. Therefore, in studies of unfamiliar lava flows (such as on Mars), areas of CVP must be identified and avoided before interpretation of 


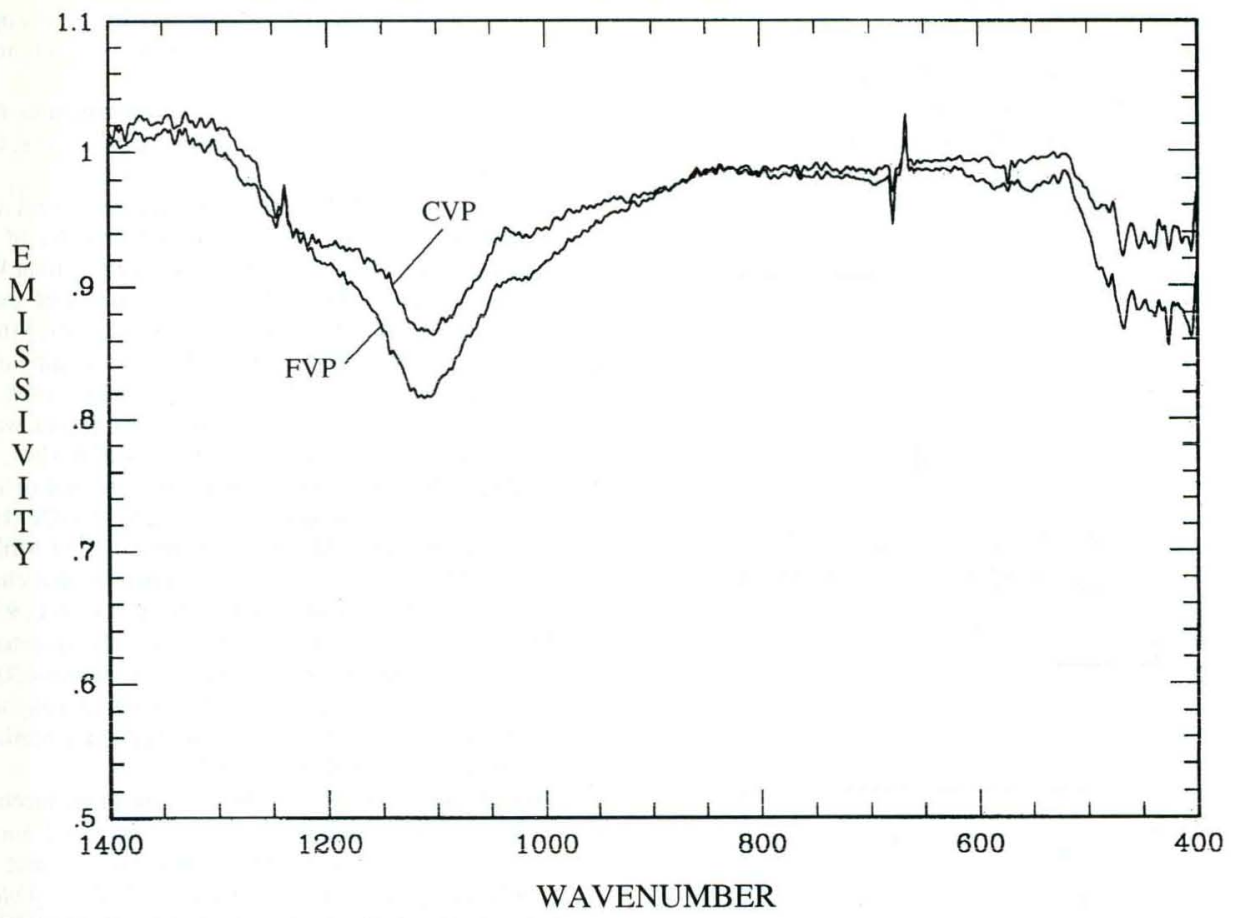

Fig. 5. High-resolution infrared emission spectra of Little Glass Mountain CVP (upper) and FVP (lower). Vertical axis is emissivity, which is dimensionless. Both spectra show the characteristic silica absorption feature at about 1100 wavenumber, in the vicinity of TIMS Band 2 (1163-1111 wavenumber) and TIMS Band 3 (1111-1063 wavenumber). Note that the CVP absorption feature is less well developed than that of FVP and thus more like that of a blackbody.

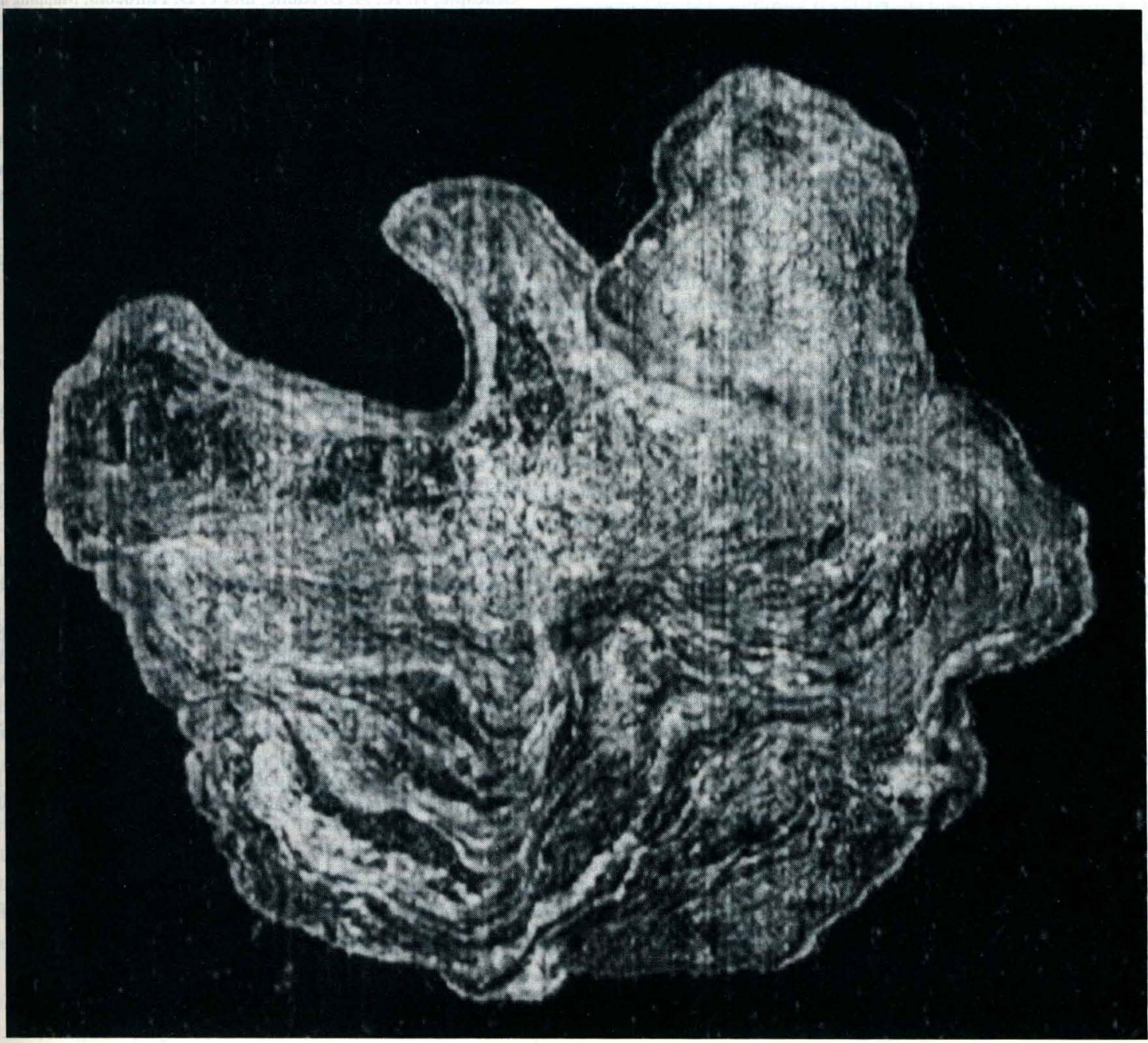

Fig. 6. TIMS image of Little Glass Mountain created using a ratio of TIMS Bands 4 and 3. Pixel size is $4.5 \mathrm{~m}$ square. Dark gray areas on image correlate well with dark gray areas in the aerial photograph of Little Glass Mountain (Figure 3) known to be diapirs of CVP. North is to the top. 

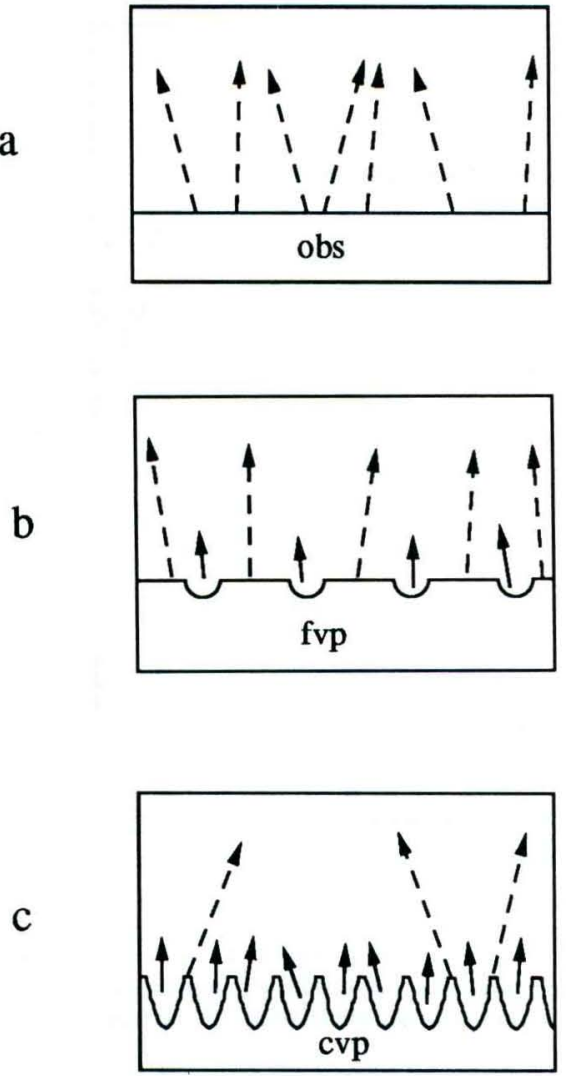

Fig. 7. Schematic representation of thermal emission processes occurring in lava of various textures. (a) Glassy obsidian emits thermal radiation (dashed arrows) with spectral characteristics dependent on the chemical composition of the glass. (b) Finely vesicular pumice emits characteristic thermal radiation, but small cavities emit blackbody radiation (solid arrows), in effect "diluting" the characteristic thermal spectrum. (c) The surface of coarsely vesicular pumice is dominated by larger and deeper cavities, which produce enough blackbody radiation to hide the characteristic radiation from the glassy septa, thus obscuring compositional information in the overall spectrum.

chemical variations can proceed. In studies of terrestrial flows, the ability to map textural variations is useful because of the significance of coarsely pumiceous lavas in volatile migration, emplacement history, and explosive hazards. Although CVP can be identified on aerial photographs of some very young rhyolitic flows, it is not at all obvious on flows of less silicic compositions; those differences are detectable to TIMS. In addition, TIMS data can be reduced to quantified units, which can then be readily calibrated and correlated with other kinds of physical data, such as laboratory spectra; variations in the visible electromagnetic spectrum, such as those observed in aerial photographs, are more difficult to so calibrate.

This new understanding of the nature of textural variations in TIMS imagery of lavas opens the way for investigations of magma mixing and other geochemical processes in more complex silicic flows. Our preliminary analysis of TIMS data for FVP samples from Glass Mountain indicates that recognition of compositional variations will be straightforward.

Acknowledgments. Thanks to Mike Ramsey for assistance with the image processing and data analysis and to Steven Anderson for discussions about lava textures. Julie Donnelly-Nolan provided a helpful review of the manuscript and valuable logistic and scientific advice in the field. Alan Gillespie also gave a very useful review. Research supported by NASA grant NAGW-529 from the Planetary Geology and Geophysics Program, and NSF grant EAR 90-18216.

\section{REFERENCES}

Anderson, C. A., Volcanoes of the Medicine Lake highland, California, Univ. Calif. Bull. Dep. Geol. Sci., 25, 347-422, 1941.
Anderson, S. W., and J. H. Fink, Hydrogen isotope evidence for extrusion mechanisms of the Mount St. Helens lava dome, Nature, 341, 521-523, 1989.

Anderson, S. W., and J. H. Fink, Crease structures: Indicators of emplacemen rates and surface stress regimes of lava flows, Geol. Soc. Am. Bull., 104, 615-625, 1992.

Bedford, R. E., Calculation of effective emissivities of cavity sources of thermal radiation, in Theory and Practice of Radiation Thermometry, edited by E. P. Dewitt and G. D. Nutter, John Wiley, New York, 1988.

Blake, S., and J. H. Fink, The dynamics of magma withdrawal from a stratified dyke, Earth Planet. Sci. Lett., 85, 516-524, 1987.

Carrigan, C. R., and J. C. Eichelberger, Zoning of magmas by viscosity in volcanic conduits, Nature, 343, 248-251, 1990.

Centeno, M., The refractive index of liquid water in the near infrared spectrum, J. Opt. Soc. Am., 31, 244-274, 1941.

Donnelly-Nolan, J. M., A magmatic model of Medicine Lake Volcano, California, J. Geophys. Res., 93, 4412-4420, 1988.

Donnelly-Nolan, J. M., D. E. Champion, C. D. Miller, T. L. Grove, and D. A. Trimble, Post-11,000 year volcanism at Medicine Lake Volcano, Cascade range, northern California, J. Geophys. Res., 95, 19693-19704, 1990.

Eichelberger, J. C., Vesiculation of mafic magma during replenishment of silicic magma reservoirs, Nature, 288, 446-450, 1980.

Fink, J. H., Structure and emplacement of a rhyolitic obsidian flow: Little Glass Mountain, Medicine Lake highland, northern California, Geol. Soc. Am. Bull., 94, 362-380, 1983.

Fink, J. H., and C. R. Manley, Origin of pumiceous and glassy textures in rhyolite flows and domes, Spec. Pap. Geol. Soc. Am. 212, 77-88, 1987.

Fink, J. H., and C. R. Manley, Explosive volcanic activity generated within advancing silicic lava flows, IAVCEI Proc. Volcanol., 1, 169-179, 1989.

Fink, J. H., S. W. Anderson, and C. R. Manley, Textural constraints on effusive silicic volcanism: Beyond the permeable foam model, J. Geophys. Res., 97, 9073-9084, 1992.

Fink, J. H., and S. W. Kieffer, Estimate of pyroclastic flow velocities resulting from explosive decompression of lava domes, Nature, 363,612-615, 1993.

Gillespie, A. R., A. B. Kahle, and F. D. Palluconi, Mapping alluvial fans in Death Valley, CA, using multichannel thermal infrared images, Geophys. Res. Lett., 11, 1153-1156, 1984.

Heiken, G., Plinian-type eruptions in the Medicine Lake highland, California, and the nature of the underlying magma, J. Volcanol. Geotherm. Res., 4, 375-402, 1978.

Kahle, A. B., A. R. Gillespie, E. A. Abbott, M. J. Abrams, R. E. Walker, G. Hoover, and J. P. Lockwood, Relative dating of Hawaiian lava flows using multispectral thermal infrared images: A new tool for geologic mapping of young volcanic terranes, J. Geophys. Res., 93, 15239-15251, 1988.

Lahren, M. M., R. A. Schweickert, and J. V. Taranik, Analysis of the northem Sierra accreted terrane, California, with airborne thermal infrared multispectral scanner data, Geology, 16, 525-528, 1988.

Lyon, R. J. P., Analysis of rocks by spectral infrared emission (8 to 25 microns), Econ. Geol., 60, 715-736, 1965.

Manley, C. R., and J. H. Fink, Internal textures of rhyolite flows as revealed by research drilling, Geology, 15, 549-552, 1987.

Palluconi, F. D., and G. R. Meeks, Thermal Infrared Multispectral Scanner (TIMS): An investigator's guide to TIMS data, Rep. 85-32, 14 pp., Je Propul. Lab, Pasadena, Calif., 1985.

Rose, W. I., Jr., T. Pearson, and S. Bonis, Nuee ardente eruption from the foot of a dacite flow, Santiaguito Volcano, Guatemala, Bull. Volcanol., 40,53. 70, 1977.

Salisbury, J. W., and J. W. Eastes, The effect of particle size and porosity on spectral contrast in the mid-infrared, Icarus, 64, 586-588, 1985.

Salisbury, J. W., L. S. Walter, and D. D'Aria, Mid-infrared (2.5 to 13.5) spectra of igneous rocks, U.S. Geol. Surv. Open File Rep. 88-686, 1988.

Vogel, T. A., J. C. Eichelberger, L. W. Younker, B. C. Schuraytz, J. P. Horkowitz, H. W. Stockman, and H. R. Westrich, Petrology and emplacement dynamics of intrusive and extrusive rhyolites of Obsidian Dome, Inyo Craters volcanic chain, eastern California, J. Geophys. Res., 94, 17937-17956, 1989.

Westrich, H. R., H. W. Stockman, and J. C. Eichelberger, Degassing of rhyolitic magma during ascent and emplacement, J. Geophys. Res., 93, 6503-6511, 1988.

P.R. Christensen, J.H. Fink, and J. Ondrusek, Department of Geology, Arizona State University, Tempe, AZ 85287-1404.
(Received January 7, 1993; revised May 17, 1993; accepted June 9, 1993.) 